\title{
PESQUISA NA ESCOLA: QUE ESPAÇO É ESSE? O DO CONTEÚDO OU O DO PENSAMENTO CRÍTICO?
}

\author{
Maria Otilia Guimarães Ninin* \\ PUC-COGEAE / UNIP-SP / CNSD-SP
}

\begin{abstract}
RESUMO: Este artigo tem como objetivo discutir o papel da pesquisa nas escolas de Ensino Fundamental e Médio, tendo como eixo fundamental a concepção de ensino na perspectiva da pedagogia crítica. Os procedimentos discutidos visam a oferecer ao professor subsídios para o trabalho com a pesquisa em sala de aula, tais que propiciem aos alunos o desenvolvimento de competências e habilidades relacionadas aos quatro pilares da educação: aprender a fazer, aprender a ser, aprender a conviver, aprender a aprender. $\mathrm{O}$ artigo está organizado da seguinte forma: a Introdução, cujo foco é a apresentação do tema "pesquisa na escola"; das seções Pesquisa: O que é?, Pesquisa: Por que e para que fazer?, Pesquisa: Como fazer?, em que discuto argumentos teóricos que sustentam a atividade de pesquisa em sala de aula; e da seção Algumas Considerações, na qual focalizo limitações e perspectivas para o trabalho do professor com pesquisa na sala de aula.
\end{abstract}

PALAVRAS-CHAVE: Pesquisa; Etapas da Pesquisa; Mediação

\section{RESEARCH IN THE SCHOOL: WHAT IS THIS SPACE: TO THE CONTENT OR TO THE CRITICAL THOUGHT? ABSTRACT}

This article aims to discuss the role of the research in Elementary and High School, considering as fundamental importance the conception of education from of the critical pedagogy. The research procedures aim to offer to the teacher a base for his/her work with the research in classroom, to offer the possibility of development of abilities to students, according the four focus: learning to make, learning to be, learning to live together and learning to

* Professora PUC-COGEAE cursos de extensão universitária; doutora em Lingüística Aplicada e Estudos da Linguagem PUC-SP; integrante de grupos de pesquisa na PUCSP, em EAD e Linguagem e Educação; Coord. Ped. Curso de Letras na UNIP; Diretora Ped. CNSD-SP. E-mail: otilianinin@terra.com.br 
learn. The article is organized from the following way: the Introduction, whose focus is the presentation of the subject "research in the school"; the sections "Research: What is it?" "Research: Why does you make one?", "Research: how do you make one?". In these sections, I discuss theoretical arguments that have supported the research activity in classroom; and "Some Considerations", where I focus limitations and perspectives about teachers' work when they use research in their classroom.

KEYWORDS: Research; Steps of the Research; Mediation

\section{INTRODUCุ̃̃O}

Vale anotar que a persistência, tão freqüiente entre nós, de modismos, como o do construtivismo ou da qualidade total, apenas confirma a precariedade em termos de competência, já que o competente se nega, terminantemente, a substituir a proposta própria por coisas vindas apressadamente de fora ou de cima para baixo. Se um dia, educar pela pesquisa virar modismo, será porque não se entendeu nada. Pedro Demo (1996/2002, p. 15)

Não escolhi Pedro Demo como inspirador das idéias que discutirei neste artigo por acaso. Ao escolher como elemento instigador a epígrafe acima, trago à tona, mais uma vez, a discussão à qual tantos educadores têm se dedicado, que aponta para a fragilidade de práticas educativas inovadoras quando suas bases teóricas não são exaustivamente discutidas. De certo modo, assim é com a pesquisa: uma prática que acompanha o educador desde longa data e que parece transformar-se nestas últimas décadas, porém, nem sempre de modo fundamentado. Quando isso ocorre, tal prática corre riscos de tornar-se um modismo, tendo seu papel reduzido a um mero pacote de informações.

Durante todo o tempo em que venho realizando trabalhos em escolas de Ensino Fundamental e Médio, em cursos de extensão universitária como coordenadora pedagógica, como coordenadora de projetos de formação de professores, como professora em cursos de formação de coordenadores e de diretores escolares, tenho me deparado com as expectativas dos participantes e muitas de suas angústias em relação ao trabalho que realizam junto aos seus alunos, quando solicitam que pesquisem sobre algum tema relacionado ao proposto a partir do currículo escolar. Essa atividade sugerida aos alunos parece, aos professores, de extrema importância e sobre ela recai, via de regra, elevado valor avaliativo - a tão cobiçada nota! 
A atividade de pesquisa, no entanto, nem sempre cumpre seu papel em relação ao desenvolvimento do pensamento crítico dos alunos e à construção de conhecimentos. Mostra-se muito mais como uma atividade em que os estudantes revelam sua dependência e sua falta de autonomia em relação à discussão de determinado assunto, visto que se resume a um texto composto de fragmentos de outros textos e/ou de informações obtidas por meio de buscas na internet, quase sempre copiadas e pouco argumentadas pelos estudantes-autores.

Também as ações de muitos professores em relação à atividade de pesquisa resumem-se, ainda, nos dias de hoje, a oferecer aos alunos um roteiro contendo: uma data para entrega do trabalho; a solicitação dos nomes dos alunos integrantes do grupo; a indicação das partes que o trabalho deve conter, como, por exemplo, introdução, objetivo, justificativa, desenvolvimento, bibliografia; a indicação dos conteúdos a serem pesquisados; além de algumas dicas orientadoras, como, por exemplo, "não faça cópia de trechos de livros", "a entrega do trabalho fora do prazo implica diminuição na nota", entre outras.

Certamente, atividades de pesquisa assim conduzidas não podem ser consideradas como desencadeadoras do pensamento crítico dos alunos, uma vez que pouco ou nada exploram seus pontos de vista e, menos ainda, propiciam ambientes para que a argumentação seja exercitada. Nessa perspectiva, a atividade não cria possibilidades para que o professor exerça seu papel de mediador na construção dos conhecimentos de seus alunos, pois o trabalho final é o que importa, e não seu processo de construção. Transforma-se a pesquisa, dessa maneira, em um instrumento avaliativo do tipo exame, o que, segundo Luckesi (2000), é representativo de uma prática avaliativa que não se preocupa com o processo, mas, sim, com o produto realizado pelo aluno, ou seja, uma prática que desconsidera o papel do aluno como ator e investigador crítico do conhecimento, para vê-lo somente como reprodutor dos conhecimentos já estáveis socialmente e que julga secundária a intervenção permanente do professor no processo de desenvolvimento do aluno ao realizar a pesquisa.

Essa visão da atividade de pesquisa vem sendo discutida por especialistas da área de educação e em cursos voltados para o conhecimento didático-pedagógico, com o propósito de oferecer aos docentes novos caminhos que os auxiliem na tarefa de orientar alunos em relação ao ato de pesquisar. Nessa direção, este artigo pretende conceituar pesquisa a partir de uma visão crítica de construção de conhecimento, bem como discutir possíveis procedimentos que ofereçam aos profes- 
sores subsídios para que propiciem aos seus alunos oportunidades para o desenvolvimento de competências como, por exemplo, ser capaz de discutir, aceitar e fundamentar diferentes pontos de vista, de criticar informações das diversas fontes consultadas, de entender a organização do conhecimento científico, de conviver e interagir em grupo, de utilizar adequadamente, com autonomia e independência, recursos tecnológicos nos encaminhamentos dos estudos.

Avançar nesse sentido, no entanto, implica, inicialmente, optar por um significado de pesquisa que seja compatível com a concepção de ensino-aprendizagem que prioriza o papel do aluno como construtor do conhecimento, o papel do professor como mediador nessa construção e o papel da atividade de ensino como instrumento-e-resultado (NEWMAN; HOLZMAN, 1993/2002), o que, na concepção vygotskyana, significa "atividade que, na medida em que se desenrola, transforma a si própria, transformando o próprio contexto e aquele que dela participa". Nessa perspectiva, a seção a seguir conceitua o ato de pesquisar, para, depois, prosseguir na discussão sobre o papel do aluno, do professor e da atividade.

\section{PESQUISA: 0 QUE É?}

Mais do que o ensino, a aplicação da pesquisa na escola conduz ao domínio das habilidades didáticas renovadoras pela discussão, pela leitura, pela observação, pela coleta de dados para comprovação de conjecturas sobre os fatos pela análise criativa das deduções, conclusões e, sobretudo, pela reconstrução do conhecimento a partir daquilo que os alunos já sabem. Jorge S. Martins (2001, p. 45)

Embora saibamos que a palavra "pesquisa" tem origem na palavra latina perquiro, que quer dizer "procurar cuidadosamente, em todo lugar e de modo aprofundado, perguntar sobre, descobrir", devemos reconhecer que "pesquisa na escola" carrega esses significados, bem como tantos outros relacionados à concepção de ensino que orienta as ações de um professor quando solicita de seus alunos uma pesquisa. Podemos pensar nesse significado que acabo de apontar do ponto de vista do professor detentor do saber: aquele que oferece aos seus alunos o conhecimento pronto e acabado ou, em situação de pesquisa, faz indicações precisas e "fechadas" para que seus alunos ampliem seu arsenal de informações. Podemos pensar, por outro lado, no significado de pesquisa do ponto de vista do professor que se apresenta aos alunos como um parceiro na construção do conhecimento e, para isso, oferece indicações "abertas", que instigam a curiosidade dos alunos em relação ao assunto estudado. 
Pesquisar, na concepção educacional que se preocupa com o desenvolvimento da autonomia do educando, não se esgota ou termina quando este encontra dados relevantes sobre um tema proposto. Ao contrário, está aí o ponto inicial do processo: dado um tema e os materiais que dizem respeito a ele, como transformar tudo isso em estudos mais aprofundados, capazes de propiciar aos alunos contextos em que ocorram debates de idéias, em que a criatividade seja aguçada, em que o espaço para perguntar e discutir seja garantido aos alunos?

Nesse sentido, podemos definir "pesquisa escolar" como atividade sistematizada e mediada entre sujeitos, pautada em instrumentos que propiciam a construção do conhecimento e o desenvolvimento da autonomia, por meio de ações com características de reflexão crítica ${ }^{1}$, que priorizam descobrir, questionar, analisar, comparar, criticar, avaliar, sintetizar, argumentar, criar.

Ao definir pesquisa dessa maneira, estamos afirmando que essa atividade não é algo para ser realizado apenas pelo aluno. Se ela é, por definição, uma atividade mediada, então é porque dela participam sujeitos e instrumentos mediadores na construção do conhecimento. Nessa direção, vale ressaltar o que afirma Demo (1992, p. 2) sobre pesquisa na escola:

A pesquisa na escola é uma maneira de educar e uma estratégia que facilita a educação (...) e a consideramos uma necessidade da cidadania moderna. (...) Educar pela pesquisa é um enfoque propedêutico, ligado ao desafio de construir a capacidade de reconstruir, na educação básica e superior (...) A pesquisa persegue o conhecimento novo, privilegiando com seu método, o questionamento sistemático crítico e criativo.

Essa é a perspectiva adotada neste artigo, ou seja, a de que o ato de pesquisar requer um educador que, exercendo seu papel de mediador, abre novos caminhos para seus alunos em direção à investigação, questionando-os e permitindo que questionem, visando a ultrapassar o saber superficial pautado no acúmulo de informações.

No entanto, para que a pesquisa seja assim concebida e entendida na escola, é preciso que professores e alunos conheçam as razões pelas quais se faz pesquisa: por que fazer e para que serve? Quando nos referimos ao "por que fazer pesquisa", estamos focalizando os objetivos da ação de pesquisar, relacionados às competências que um aluno desenvolve quando executa esse trabalho. Quando nos referimos ao "para que serve a pesquisa", estamos nos referindo às razões práticas que envolvem o trabalho de pesquisar, relacionadas às habilidades que um aluno desenvolve quando faz pesquisa. A seção a seguir discute as competências e habili- 
dades envolvidas na ação de pesquisar, quando orientadas permanentemente pelo professor.

\section{PESQUISA: POR QUE E PARA QUE FAZER?}

- Conte-me um pouco sobre as pesquisas em sua escola.

- Ab, são muitas. Todos os professores dão pesquisa para ajudar na nota. Principalmente quando a gente vai mal na prova.

- E aí, o que é que vocês fazem?

- Bom, a gente se reúne, divide o que vai fazer, procura na internet e faz.

- Mas... só copiam da internet?

- Mais ou menos. Tem gente que sabe resumir e ai o trabalho fica melhor. Quando cai para mim uma parte que eu consigo entender, até faço o resumo, mas às vezes o texto é difícil e ai a gente copia.

- Epode fazer isso?

- Pode, mas tem que pôr o nome do site na Bibliografia.

- Você aprende muito com as pesquisas?

- Acho que sim, porque eu recupero minhas notas. Mas en gosto mais quando a gente faz. trabalhos de fazer mesmo alguma coisa, assim tipo fazer uma experiência, fazer um debate... Isso é meIhor porque a gente pode falar mais o que a gente pensa. Eu fico intrigado e ai eu quero fazer mesmo.

Aluno de $7^{\mathrm{a}}$ série do Ensino Fundamental (2005)

O depoimento anterior, selecionado entre vários coletados em escola regular de Ensino Fundamental durante a realização de um encontro de formação contínua para professores, revela-nos, de modo intrigante e profundamente sensível, o nível de conscientização de um estudante sobre o significado real da pesquisa em sua vida. Revela-nos, por outro lado, a importância dada por ele ao pensar com mais profundidade sobre algo, pois, caso isso não ocorresse, não diria "eu fico intrigado e aí eu quero fazer mesmo". Revela-nos, também, que existe um "rótulo" cristalizado para a pesquisa, capaz de desvinvulá-la da ação de pensar.

"Fico intrigado..." Nessa linguagem própria do adolescente, não estaria ele nos dizendo que pesquisar e pensar para descobrir, para criar, são atividades opostas?

Se perguntarmos aos professores "para que serve a pesquisa", certamente responderão que, entre outras coisas, "pesquisa serve para ampliar os conhecimentos dos alunos sobre um dado assunto". Também para os alunos, como vimos, o significado de pesquisar parece ser esse mesmo. Ora, o que acontece, então, durante a caminhada, que faz com que professores critiquem a cópia e a repetição apresentadas pelos alunos, e estes, por sua vez, critiquem o enorme peso com o qual se vêm envolvidos ao cumprirem a tarefa de pesquisar?

Parece que há um ponto de convergência em relação a essas críticas: ambos - professores e alunos -, nessas condições, estão preocupados 
apenas com o resultado da pesquisa e não com o processo de pesquisar. Preocupar-se, prioritariamente, com o resultado da pesquisa, ainda que seja para pensar nela como "ampliação dos conhecimentos dos alunos", implica entendê-la como instrumento-para-resultado (NEWMAN; HOLZMAN, 1993/2002), conceito vygotskyano que significa o uso de um dado instrumento para se obter um fim, sem que o instrumento seja compreendido ou questionado, em sua concepção, pelo sujeito que o utiliza.

Se considerarmos a pesquisa como esse instrumento oferecido ao aluno, será a mediação do professor aquela que proporcionará tanto a transformação do próprio instrumento - na medida que a pesquisa se modifica e oferece a possibilidade de articulação com outras áreas do conhecimento - quanto a transformação do aluno - que se dá a partir das oportunidades surgidas ao se colocar em prática as ações que definem pesquisar, ou seja: descobrir, questionar, analisar, comparar, criticar, avaliar, sintetizar, argumentar, criar.

Nessa direção, a pesquisa abre espaços para que o aluno trabalhe com suas indagações pessoais e desenvolva opiniões próprias, fundamentadas, a respeito dos temas pesquisados. A pesquisa é, então, entendida como um instrumento problematizador que, quando planejada e mediada pelo professor, faz do aluno-copiador um aluno-pesquisador.

Um fato relevante, no entanto, tem impedido que os alunos transformem-se nesses pesquisadores descritos: seus professores, muitas vezes conduzidos por crenças em práticas educacionais que viveram quando estudantes e por processos de formação docente que privilegiaram discussões sobre estratégias de ensino pautadas na transmissão do conhecimento e no poder da quantidade de informações, vêem-se despreparados para orientar seus alunos em relação à tarefa de pesquisar. Acabam por enfatizar os grandes temas propostos nos livros didáticos, acreditando que, para conhecê-los, os alunos precisam apenas escrever exaustivamente sobre eles. Assim, as pesquisas são propostas aos alunos a partir de tópicos de conteúdos curriculares e os alunos são incentivados a ir à biblioteca para coletar dados escritos por diferentes autores e compilá-los, em um único texto. Outras propostas de pesquisa estão orientadas a temas atuais e, para isso, os alunos recorrem à internet ou a revistas e jornais. Nesse caso, seriam necessárias orientações precisas sobre como os alunos deveriam estabelecer relações entre o tema da atualidade e os fundamentos teóricos estudados em sala de aula. Caso essas orientações não sejam explicitadas na proposta de pesquisa ou não sejam discutidas em sala de aula, os trabalhos tendem a limitar-se ao fato em si ou, quando muito, a efeitos que causa no meio social. 
Interessante ressaltar uma afirmação de Oliveira et al. (1999, p. 42) sobre os motivos que levam os professores a solicitarem pesquisas de seus alunos: "em primeiro lugar, para complementar conteúdos e, em segundo, para antecipar conteúdos". Motivos como argumentar, ampliar conhecimentos, aprofundar e enriquecer os conteúdos, criar hábitos de leitura são menos apontados por professores. Já motivos como criticar e criar não foram encontrados nos depoimentos dos professores pesquisados.

Para discutirmos por que e para que fazer pesquisa é importante considerar que todas as competências e habilidades que um aluno poderá desenvolver a partir desse trabalho passam, em primeiro lugar, pela intencionalidade dos professores e por sua co-responsabilidade em relação ao fazer do aluno e à sua aprendizagem.

Assim, escolher temas para pesquisa que exijam dos estudantes apenas ações de busca sobre um assunto e que não necessitem de intervenção naquilo que escrevem e/ou copiam não possibilita o desenvolvimento da competência de argumentar e criticar o que estudam, como também não possibilita a formação do aluno autônomo e crítico. Por exemplo: pesquisar sobre as obras e a vida de Picasso pode ser uma tarefa para a qual os alunos apenas exercitam a habilidade de compilar diferentes informações sobre o artista, ao passo que pesquisar como e por que alguns artistas contemporâneos produzem obras sob a influência de Picasso pode exigir uma competência dos alunos voltada à comparação e à análise de obras artísticas, situadas social e culturalmente. Ideal seria, ainda, que uma pesquisa com esse propósito desencadeasse discussões sobre o papel da arte na vida humana, o papel da arte da vida do estudante-autor, a relevância da arte em nossa cultura...

Em vez de solicitar uma pesquisa sobre a Floresta Amazônica e a biodiversidade, que provavelmente poderá ser cumprida pelos alunos apenas mediante buscas na internet, o professor poderá propor algo que exija do aluno relacionar a biodiversidade na Amazônia e a extinção de diversas espécies da flora e da fauna ao papel do homem amazonense e do homem não-amazonense em relação ao meio ambiente. Solicitada dessa forma, a pesquisa exigiria do aluno competências e habilidades voltadas às ações de relacionar, analisar, argumentar, expressar pontos de vista e discutir valores éticos, o que, certamente, contribuiriam para a formação do aluno como sujeito crítico. Estaria, ainda, colocando no centro das discussões o próprio aluno (seja ela amazonense ou não) e sua responsabilidade social.

No entanto, todas essas competências não se desenvolvem senão pelas ações mediadoras de alguém com maior experiência e com conhe- 
cimentos específicos em relação ao tema tratado. Notem que não digo "com domínio completo do tema tratado", pois sabemos não ser possível esse domínio, uma vez que o mundo está em constante transformação e os conhecimentos que tínhamos ontem não necessariamente permanecem os mesmos hoje.

Nas situações escolarizadas, podemos dizer que reside aí o papel do professor. Competências só poderão ser desenvolvidas em "ambientes de aprendizagem", denominação cunhada por Demo (2004, p. 9), ao considerar a pesquisa uma "proposta formativa essencialmente, e não apenas tática de fazer conhecimento". $\mathrm{Na}$ visão do autor, o "fazer pesquisa" provoca transformações no aluno, em direção à construção da autonomia para pensar. "Na medida que o aluno pesquisador aprende a duvidar, questionar, argumentar, fundamentar, ouvir o outro com atenção e responder, convencer sem vencer, não só faz conhecimento, como principalmente, se forma". Mas, para aprender tudo isso, é preciso um professor que instigue o aluno a duvidar do que encontra na internet, por exemplo; é preciso um professor que responda perguntas com outras perguntas, que discuta o "como fazer" durante o fazer e não quando tudo já está terminado. Ao término do processo, o que resta é o julgamento do resultado: "a pesquisa está ótima! faltou isso, faltou aquilo na pesquisa! Aqui vocês acertaram, aqui vocês erraram; é preciso apresentar o resultado para os colegas; melhorem, na próxima vez...”.

Essa perspectiva nos leva a discutir procedimentos para se fazer pesquisa em sala de aula, acreditando que as diferentes ações dos professores e de seus alunos no decorrer do processo de pesquisar é que propiciam o desenvolvimento das competências discutidas anteriormente. A seção a seguir ocupa-se dessa discussão.

\section{PESQUISA: COMO FAZER?}

Não vim aqui, disse eu, para fazer um discurso, mas para conversar. Farei perguntas, vocês também. As nossas respostas darão sentido ao tempo que passaremos juntos aqui.

Parei. Houve um silêncio cortado por um deles que falou: - Muito bem, acho que é bom assim. Realmente não gostariamos que você fizesse um discurso. Tenho já uma primeira pergunta. - Pois não, disse eu. - O que significa mesmo perguntar?

Insistimos, porém, em que o centro da questão não está em fazer com a pergunta "o que é perguntar?" um jogo intelectual, mas viver a pergunta, viver a indagação, viver a curiosidade, testemunbá-la ... Paulo Freire (1985/2002, p. 47-48) 
Até este momento, nossa discussão encaminhou-se no sentido de explorarmos os conceitos teóricos que possibilitam ao professor compreender o processo de pesquisa e sua relação com a aprendizagem dos alunos. Esta seção pauta-se em questões de ordem prático-teórica e orientará os passos para a realização de uma pesquisa.

Ao entendermos pesquisa como o espaço para a construção do conhecimento novo, pautado no questionamento, que busca o desenvolvimento do sujeito crítico, historicamente situado, o professor não poderá seguir modelos convencionais de trabalho, mas terá de planejar momentos de intervenções precisas e sistematizadas junto aos seus alunos. Isso vai desde a organização dos grupos e orientações sobre como trabalhar coletivamente à condução, passo a passo, do desenvolvimento do trabalho.

Planejar intervenções implica preparar questionamentos para fazer aos alunos, dado que estes, ao desenvolverem suas pesquisas, nem sempre são capazes de abstrair, de maneira crítica, os significados implícitos que permeiam seus trabalhos. Para questionar o aluno, no entanto, o professor precisa de elementos teóricos que o auxiliem a elaborar perguntas capazes de trazer à tona os conhecimentos prévios de cada um sobre o tema proposto e aí está o ponto de partida: que perguntas fazer, em classe, para descobrir o que os alunos já conhecem e o que já são capazes de expressar por meio de saber crítico, em relação ao tema pretendido para pesquisa?

Em outras palavras, quero dizer que assim como o conhecimento prévio de um grupo de alunos não é igual ao de outro, também a pesquisa de um grupo não será igual à de outro. Implicações disso nos levam a crer que a pesquisa conduzida nessa perspectiva não resultará em "vários trabalhos entregues ao professor, todos quase iguais ou, o que é pior, iguais, elaborados a partir das mesmas fontes, copiados dos mesmos materiais...".

Nessa perspectiva, a pesquisa se desenvolve na individualidade do grupo de alunos, a partir dos elementos que, para cada grupo específico, constituem-se fatores de dúvida, curiosidade, inovação, encantamento. Assim, o primeiro passo, para o aluno, constitui-se na organização do grupo de trabalho. Parece aos professores que essa questão não exige sua intervenção, no entanto, sabemos que, em função de diferentes objetivos idealizados para o trabalho, as diferentes participações nos grupos fazem a diferença. Quero dizer com isso que há propostas de trabalho que exigirão grupos com diferentes habilidades, enquanto que outras poderão ser 
levadas a cabo por participantes com habilidades similares; há propostas que exigirão grupos com conhecimentos prévios semelhantes, enquanto que para outras propostas seria fundamental grande diversidade de conhecimentos prévios. Ou seja, nem sempre é conveniente que o grupo se organize a partir de critérios como "alunos que têm afinidade um com o outro". Dados os objetivos do trabalho, cabe ao professor definir critérios para a organização do grupo e nem sempre esses critérios privilegiam as afinidades entre os alunos. O que importa, certamente, é que estes compreendam claramente os critérios utilizados para a formação dos grupos.

Uma vez o grupo organizado, um segundo passo a ser dado refere-se à elaboração de um projeto preliminar de pesquisa com indicações claras sobre os pontos pretendidos para o desenvolvimento da investigação. "Pontos pretendidos". Vejam a importância desse fato. Não se espera, nesse momento, que o trabalho dos alunos encerre-se nesse índice preliminar e, a partir dele, se desenvolva. Se levarmos em conta o significado de projeto, entenderemos que esse é apenas o momento de lançar para frente as idéias. Aonde se quer chegar com isso não pode ser definido a priori, pois dependerá da motivação, curiosidade e inventividade dos alunos. Tudo isso significa idealizarmos um objeto e nos projetarmos em direção a ele.

Já aí, o papel do professor como mediador é fundamental. Será por meio de suas perguntas precisas, diferentes para cada grupo de alunos, que estes poderão reorientar a rota da pesquisa, seja para inserir novos itens ou para manter aqueles escolhidos. A elaboração do projeto, no entanto, não pode ser algo a ser concebido pelo grupo sem orientações. Para isso, o professor poderá solicitar, como tarefa, um levantamento de materiais que focalizem o assunto escolhido para a pesquisa. Tais materiais deverão ser socializados em sala de aula e, a partir de então, os diferentes grupos, mediante seus conhecimentos prévios e os questio-namentos apresentados pelo professor, elaborarão seus projetos de pes-quisa. Vale ressaltar que, até então, a atividade "pesquisa" ocorre acom-panhada "de perto" pelo professor. Descarta-se, portanto, aquele dizer do tipo "pesquisa para dia tal”! Imprevistos também podem ocorrer em relação aos materiais selecionados para uma pesquisa: nem sempre estão disponíveis ou são de fácil acesso aos alunos ou, ainda, adequados à faixa etária. Também nesse momento, o professor tem papel fundamental: deixar emergir sua criatividade e provocar a motivação dos alunos, apresentando, ele próprio, materiais relevantes ao estudo. $\mathrm{Na}$ verdade, materiais apresentados pelo próprio professor podem significar a garantia de que a pesquisa será encaminhada de modo a alcançar os objetivos propostos. 
Cabe, neste momento, um lembrete importante sobre materiais encontrados na internet. Sabemos que nem tudo o que está disponível na web é confiável e sabemos, também, que nossos alunos nem sempre são capazes de julgar a qualidade desses materiais. Assim, temos duas opções interessantes: uma delas refere-se à indicação de sites oficiais para pesquisa, entre eles, os de universidades. A outra opção, certamente de ordem crítica, constitui-se em aceitar os diferentes materiais e ensinar o aluno a comparar e questionar aqueles que apresentam informações imprecisas e/ou incorretas. O trabalho monográfico dos alunos poderá conter comparações e discussões sobre as divergências existentes entre os materiais encontrados sobre o tema.

O terceiro passo a ser dado constitui-se em elaborar textos preliminares relacionados ao foco da pesquisa. Mas também aí o professor não pode estar afastado. Como garantir que os alunos façam uso do gênero científico na elaboração de seus textos? Sabemos que cada ciência tem suas características próprias no que se refere à produção de textos e à terminologia utilizada. A linguagem específica, portanto, requer ser ensinada ao aluno. Quero dizer, com isso, que um texto científico é exigente: não permite o uso de julgamentos e juízo de valor; não pode conter opiniões sem que sejam fundamentadas; necessita objetivos explícitos, elaborados a partir de escolhas lingüísticas adequadas²; organiza-se a partir de seções específicas que não podem ser excluídas do texto.

Bagno (1999) orienta a elaboração do projeto, indicando as seções básicas que devem ser produzidas pelos alunos ao longo do trabalho de pesquisa: escolha de um título sugestivo; elaboração textual do objetivo do trabalho; elaboração textual da justificativa para a realização do trabalho e do estudo do tema; descrição metodológica de todos os procedimentos realizados, desde as discussões sobre as escolhas temáticas às relacionadas à análise de materiais; desenvolvimento do tema; relação das fontes pesquisadas; cronograma indicativo das etapas previstas para o trabalho.

Cada um dos itens apontados corresponde a diferentes momentos disponibilizados pelo professor para acompanhar o processo de desenvolvimento do trabalho de seus alunos. Assim, quando os projetos dos estudantes forem apresentados em classe, deverão ser discutidos e reelaborados, caso necessário. Nunca descartados! O papel do professor - que certamente tem um objetivo claro a ser alcançado com o trabalho - deverá ser o de acolher as diferentes idéias e oferecer aos alunos novos encaminhamentos para que seja contemplado seu objetivo maior. 
Em relação à justificativa para a realização do trabalho, não é tão simples quanto parece. Ela corresponde à relevância que esse trabalho deve ter e relevância significa pensar no papel social que o trabalho exerce na vida do aluno. Por que e para que fazer esse trabalho, com esse tema, com esses elementos, é fator importante para o desenvolvimento do aluno? Assim, um trabalho que focalize apenas um bloco de conhecimentos específicos, sem estabelecer relações com as práticas sociais com as quais o aluno está envolvido, não pode ser considerado relevante. Seria apenas para ampliar os conhecimentos específicos do aluno, ou melhor, a quantidade de informações que retém. Justificativas exigem relação entre o conteúdo escolhido para estudo e seu papel no desenvolvimento do educando.

Uma etapa do processo de pesquisa está centrada na leitura dos textos selecionados e na elaboração dos fichamentos. Isso não significa que o texto final do trabalho conterá esses fichamentos, mas, certamente, conterá a articulação entre eles. Essa tarefa vai desde a ação de destacar palavras-chave do texto e idéias mais relevantes até a elaboração de novo texto que as contenha, construído de modo argumentado, objetivo e claro. Aí também é imprescindível a presença do professor, pois somente ele, seguidor do processo, terá como apontar aos alunos as incoerências e inadequações presentes nos textos elaborados.

Ora! Mas isso não se faz ao final do trabalho, quando o tempo já se encerrou. Isso se faz durante o andamento do trabalho, ou seja, o professor oferece aos alunos momentos intermediários para discussão sobre o material já produzido. Vejamos: esses momentos não são simples orientações sobre o que será feito, mas sobre o que já foi feito até então, o que requer do professor a leitura dos textos já produzidos por seus alunos e não apenas uma olhada. É exatamente nesses momentos que a mediação do professor pode ser eficaz no sentido de gerar conflitos para que os alunos façam novas buscas, sintam-se intrigados com suas próprias conclusões, duvidem do que já produziram e recorram a novos caminhos. É exatamente nesses momentos que o professor informa os pontos não completamente satisfatórios do trabalho, em relação aos conhecimentos conceituais, procedimentais, atitudinais e factuais ${ }^{3}$ dos alunos, revelados até então no que já foi desenvolvido.

Também pode ser considerada uma das etapas do trabalho de pesquisa a reelaboração dos textos produzidos, a partir das orientações do professor. Vale notar que, até então, não há referência a "dar nota aos alunos". Fases de refacção do trabalho não podem ser consideradas como 
etapas concluídas, mas sim etapas em processo. Reelaboração exige apontamentos precisos do professor e questionamentos sobre como o aluno poderá aprimorar o trabalho textual. Demo (1996/2002, p. 34) afirma que "o professor deve orientar o aluno permanentemente para: expressar-se de maneira fundamentada, exercitar o questionamento sempre, exercitar a formulação própria, reconstruir autores e teorias, cotidianizar a pesquisa".

Uma outra etapa é a dedicada à organização final da pesquisa. Essa também exige orientações permanentes do professor. Nesse momento, é fundamental observar se os alunos envolvidos são capazes de dividir as tarefas de maneira equilibrada, bem como orientar para que cada um se responsabilize por algo, desde os procedimentos que envolvem a digitação de textos aos relacionados à ilustração e ao design final. Diferentes competências e habilidades são envolvidas nesse momento e é preciso que o professor ofereça oportunidade para que os alunos coloquem em prática o que sabem fazer.

Também é necessário esclarecer que nem toda pesquisa culmina em trabalho escrito, do tipo monográfico. Seja qual for o produto final escolhido, requer um processo de organização cujo papel do professor é imprescindível.

Como última etapa, podemos considerar a apresentação pública do trabalho de pesquisa. Para que ela ocorra, alguns procedimentos muito importantes para os alunos deverão ser colocados em prática pelo professor, como, por exemplo, a tarefa de combinar critérios avaliativos para esse momento. Isso significa discutir com os alunos como serão avaliados no momento em que estiverem apresentando seu trabalho à classe. Por exemplo: os alunos sabem que não devem usar gíria enquanto apresentam seu trabalho? Poderão utilizá-la? Sabem que precisam explicar e não devem fazer leitura do trabalho? Sabem expor o conteúdo proposto destacando o que é mais relevante? Sabem qual é o papel do texto em uma apresentação em PowerPoint?

Nesse sentido, uma reunião anterior à apresentação poderá ser benéfica para que os alunos entendam que serão avaliados mediante critérios que contemplam: aspectos conceituais - ser capaz de aprofundar a explicação teórica, de expressá-la objetivamente, de fazer uso da linguagem de modo adequado, evitando vícios de linguagem e uso de gírias; aspectos procedimentais - ser capaz de apresentar-se a partir de uma seqüência de ações claras sobre os passos do trabalho; aspectos atitudinais - ser capaz de apresentar-se de maneira polida e responsável; aspectos 
factuais - ser capaz de situar o trabalho no contexto de ensino em que está inserido.

Somente após todas essas etapas é que um trabalho de pesquisa deverá ser avaliado no sentido de atribuir-se a ele uma nota ou um conceito. Ressalto, porém, que essa prática de atribuir nota aos trabalhos de pesquisa nem sempre pode ser considerada adequada, uma vez que pesquisa é aqui considerada um projeto permanente do aluno no decorrer das práticas educativas com as quais está envolvido em sala de aula. Se pensarmos na pesquisa como fator de desenvolvimento do aluno, não se faz necessária a nota, mas torna-se relevante descobrir como o aluno se desenvolve ao longo do trabalho realizado.

O Quadro 1 mostra, de modo sintetizado, as etapas de uma pesquisa, com indicações sobre os papéis do professor e do aluno no processo de desenvolvimento do trabalho.

\section{QUADRO 1}

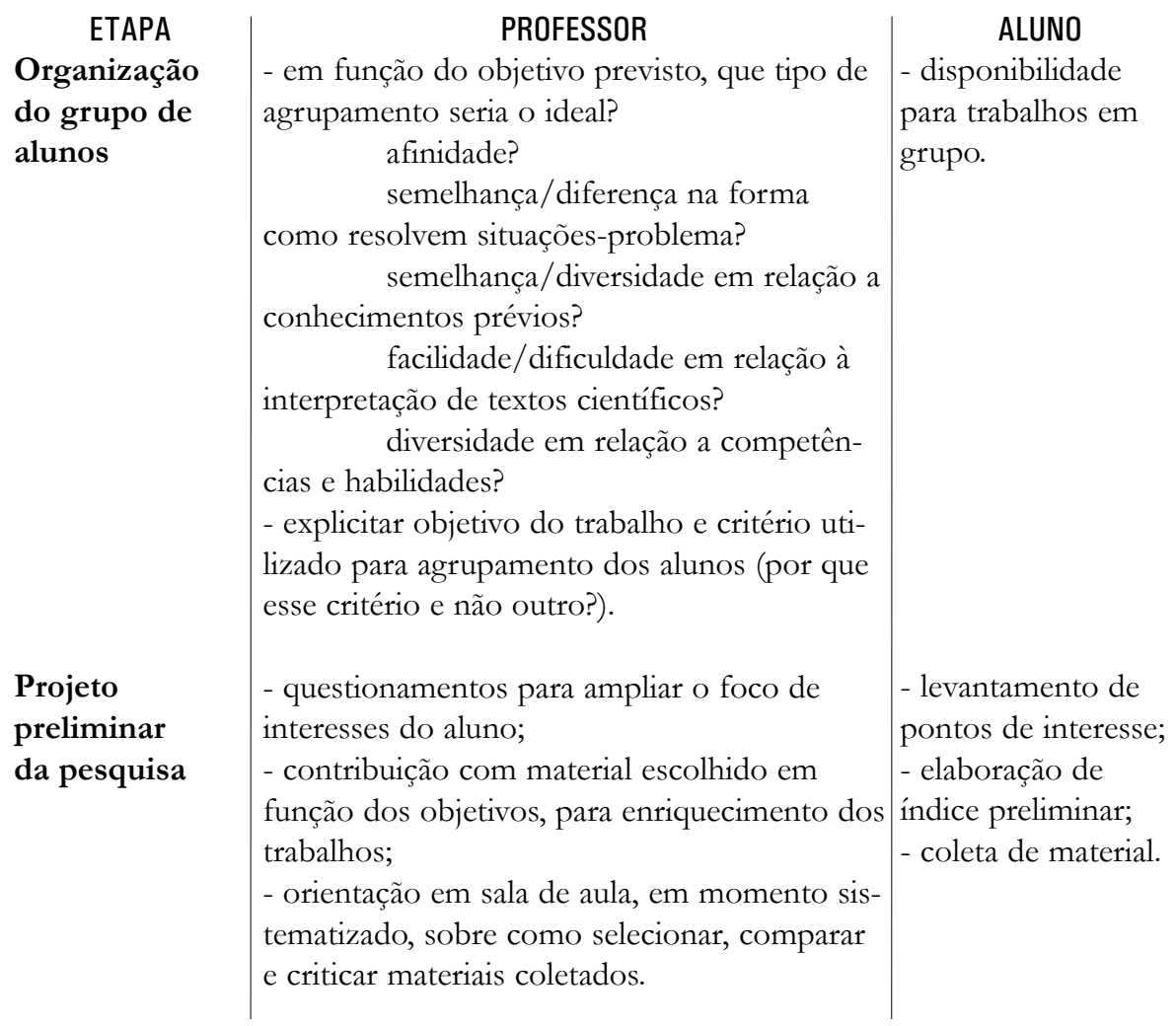


cont.

\begin{tabular}{|c|c|c|}
\hline & FFS & \\
\hline $\begin{array}{l}\text { Elaboração } \\
\text { de textos } \\
\text { preliminares }\end{array}$ & - leitura e comentário, por escrito. & $\begin{array}{l}\text { - elaboração de } \\
\text { objetivo e } \\
\text { justificativa para } \\
\text { o trabalho; } \\
\text { - reescrita. }\end{array}$ \\
\hline $\begin{array}{l}\text { Leitura de } \\
\text { textos } \\
\text { selecionados }\end{array}$ & $\begin{array}{l}\text { - orientação sistematizada sobre características } \\
\text { do gênero textual adequado (texto científico); } \\
\text { - socialização dos materiais; } \\
\text { - questionamentos para instigar o grupo a } \\
\text { novas buscas; } \\
\text { - informação sobre pontos insatisfatórios do } \\
\text { trabalho, em relação a:Ä veracidade dos } \\
\text { conceitos apresentados; } \\
\text { argumentação; } \\
\text { metodologia; } \\
\text { procedimentos; } \\
\text { responsabilidade; } \\
\text { organização geral. }\end{array}$ & $\begin{array}{l}\text { - resumos e } \\
\text { fichamentos de } \\
\text { textos; } \\
\text { - reescrita, a partir } \\
\text { da articulação entre } \\
\text { os diferentes textos. }\end{array}$ \\
\hline $\begin{array}{l}\text { Reelaboração } \\
\text { de textos } \\
\text { produzidos }\end{array}$ & - acompanhamento. & $\begin{array}{l}\text { - reescrita, a partir } \\
\text { das orientações orais } \\
\text { do professor e } \\
\text { comentários } \\
\text { apresentados nas } \\
\text { versões preliminares } \\
\text { do trabalho. }\end{array}$ \\
\hline $\begin{array}{l}\text { Organização } \\
\text { final da } \\
\text { pesquisa }\end{array}$ & $\begin{array}{l}\text { - orientações sistematizadas em função do } \\
\text { tipo de produto final desejado: } \\
\text { se vídeo, como produzi-lo? o que } \\
\text { deve ser evitado em relação às tomadas de } \\
\text { turno dos participantes? qual a duração? é } \\
\text { vídeo motivacional? é vídeo para apresentação } \\
\text { de conteúdo conceitual? como escolher quem } \\
\text { atuará? } \\
\quad \text { se texto monográfico, qual o número } \\
\text { de páginas? como ordenar o texto final? como } \\
\text { citar autores? qual o papel de trechos } \\
\text { opiados? } \\
\quad \text { se dramatização, como garantir que o } \\
\text { conteúdo conceitual seja contemplado nos } \\
\text { diálogos? como evitar senso comum? como } \\
\text { criar e distribuir os papéis? }\end{array}$ & $\begin{array}{l}\text { - elaboração e } \\
\text { discussão sobre o } \\
\text { formato da } \\
\text { apresentação, em } \\
\text { grupo e com o } \\
\text { professor. }\end{array}$ \\
\hline
\end{tabular}


cont.

\begin{tabular}{|c|c|c|}
\hline ETAPA & $\begin{array}{l}\text { PROFESSOR } \\
\text { se apresentação oral, como elaborar } \\
\text { um arquivo PowerPoint? como usar a lin- } \\
\text { guagem na produção textual dos slides? como } \\
\text { evitar vícios de linguagem? como dividir as } \\
\text { tarefas da apresentação? como ilustrar? }\end{array}$ & ALUNO \\
\hline $\begin{array}{l}\text { Apresentação } \\
\text { pública da } \\
\text { pesquisa }\end{array}$ & $\begin{array}{l}\text { - discussão e negociação para a escolha de crit } \\
\text { a apresentação e para o trabalho textual produ }\end{array}$ & avaliação para \\
\hline
\end{tabular}

\section{ALGUMAS CONSIDERACִÕES}

O paradoxo do desejo deve-se, na verdade, ao fato de que o objeto desejado deve ser, ao mesmo tempo, conhecido e desconhecido, que é preciso adivinhar os seus contornos, entrever o seu segredo, mas ele deve permanecer escondido e o segredo não deve ser penetrado. Se o papel do professor é fazer com que nasça o desejo de aprender, sua tarefa é "criar o enigma" ou, mais exatamente, fazer do saber um enigma: comentá-lo ou mostrá-lo suficientemente para que se entreveja seu interesse e sua riqueza, mas calar-se a tempo para suscitar a vontade de desvendá-lo. Philiippe Meirieu (1991/1998, p. 91-92)

Ao apontar, no resumo apresentado no início deste artigo, a existência de limitações no trabalho com pesquisa, referia-me às escolas e aos professores que fazem uso desse rico instrumento para manipular os saberes de seus alunos, ou ainda, cercear possibilidades de seu desenvolvimento, uma vez que se mantêm nos velhos modelos voltados às cópias e ao acúmulo de conteúdos e conceitos.

A falta de conhecimentos em relação aos meios tecnológicos usados para obtenção de informações também pode ser considerada uma limitação no trabalho com pesquisas, uma vez que esses meios, quando mal-utilizados e mal-orientados, transformam-se em ferramentas mecânicas disponibilizadas ao aluno. Em nada fazem crescer e, muito menos, possibilitam a ele articular conhecimentos e questioná-los.

Avançaríamos, portanto, nesse sentido, se nos preocupássemos em formar professores nas escolas capazes de discutir questões éticas relacionadas à pesquisa de seus alunos, no sentido de expor e criticar as práticas pautadas em cópias e fragmentos de diferentes autores. Avançaríamos também se provocássemos os educadores para que revisassem suas práticas e nelas inserissem mais e mais momentos de pesquisa real, 
em que os alunos pudessem trabalhar com suas expectativas, suas dúvidas e sua capacidade criativa e inventiva, em direção à produção de conhecimento e não à simples repetição daquele já existente.

Para concluir, retomo os dizeres de Pedro Demo, citado por mim na epígrafe inicial: "Se um dia, educar pela pesquisa virar modismo, será porque não se entendeu nada". Retomo para afirmar que a postura do educador frente à pesquisa e a tantos outros instrumentos de aprendizagem exige conhecimento consciente e deliberado, além de alto grau de comprometimento em relação ao seu papel de intervenção permanente no desenvolvimento do educando.

\section{REFERÊNCIAS}

BAGNO, Marcos. 1998. Pesquisa na Escola. O que é. Como se faz. 2 ed. São Paulo: Loyola, 1999.

DEMO, Pedro. Formação de Formadores Básicos. Brasília: INEP, 1992.

DEMO, Pedro. 1996. Educar pela Pesquisa. 5 ed. Campinas: Autores Associados, 2002. (Coleção Educação Contemporânea)

FISHER, Alec. 2001. Critical Thinking: an introduction. Cambridge: Cambridge University Press, 2005.

KEMMIS, S. Critical Reflection. In: WIDEEN, M.F.; ANDREWS, I. (Eds.) Staff Development for School Improvement. Philadelphia: The Falmer Press, 1987.

LEFFA, Vilson J. Como produzir materiais para o ensino de línguas. In. LEFFA, Vilson J. (Org.). Produção de materiais de ensino: teoria e prática. Pelotas: Educat, 2003.

LUCKESI, Cipriano C. Avaliação da Aprendizagem Escolar. São Paulo: Cortez, 2000.

MARTINS, Jorge Santos. O trabalho com projeto de pesquisa: do ensino fundamental ao médio. Campinas: Papirus, 2001.

MEIRIEU, Philippe. 1991. Aprender... Sim, mas Como? Trad. Vanise Pereira Dresch. 7 ed. Porto Alegre: Artmed, 1998.

NEWMAN, Fred; HOLZMAN, Lois. 1993. Lev Vygotsky - cientista revolucionário. Trad. Marcos Bagno. São Paulo: Loyola, 2002.

OLIVEIRA, Sônia M.M. et al. Diagnóstico da Pesquisa Escolar, no Ensino de $5^{a}$ a $8^{a}$ série do $1^{0}$ Grau, nas Escolas de Londrina - Paraná. Londrina: Inf. Inf. v. 4, n. 1, p. 37-50, jan./jun. 1999.

ZABALA, Antoni. A prática educativa: como ensinar. Porto Alegre: Artes Médicas, 1995.

\section{NOTAS}

${ }^{1}$ Para Kemmis (1987), reflexão crítica implica uma visão da prática como ação informada e comprometida, que leva em conta as relações entre pensamento (teoria formal) e ação. A reflexão crítica pressupõe relações sociais, ou seja, o indivíduo atuante em situações que envolvem interesses humanos, políticos e culturais, tendo como foco a metacognição. Fisher (2001/2005) afirma que é preciso desenvolver habilidades para pensar criticamente e que esse pensar crítico envolve uma competência acadêmica voltada à interpretação ativa e à avaliação de observações e comunicações, informações e argumentação. 
${ }^{2}$ Em relação à redação dos objetivos em um trabalho, uma orientação interessante é a oferecida por Leffa (2003): "Para os objetivos gerais, usam-se geralmente verbos que denotam comportamentos não diretamente observáveis. Entre esses verbos, os seguintes têm sido usados com mais freqüência: saber, compreender, interpretar, aplicar, analisar, integrar, julgar, aceitar, apreciar, criar, etc. Para os objetivos específicos, usam-se verbos de ação, envolvendo comportamentos que podem ser diretamente observados. Entre eles destacam-se: identificar, definir, nomear, relacionar, destacar, afirmar, distinguir, escrever, recitar, selecionar, combinar, localizar, usar, responder, detectar, etc. Verbos que denotam processo - aprender, desenvolver, memorizar, adquirir, etc. - não podem ser usados para elaborar objetivos educacionais; eles não descrevem o resultado da aprendizagem".

3 Os conceitos de conhecimentos factuais, conceituais, procedimentais e atitudinais baseiam-se em Zabala (1995). Conhecimentos factuais correspondem ao conhecimento de fatos, acontecimentos, situações, dados e fenômenos concretos. Conhecimentos conceituais referem-se a conjuntos de fatos, objetos ou símbolos que se organizam a partir de características comuns e articuladas, exigindo abstrações e relações com outros conhecimentos já construídos. Conhecimentos procedimentais estão relacionados ao saber faz̧er algo e o que define sua aprendizagem não é o conhecimento que se tem sobre algo, mas sim o domínio ao transferi-lo para situações práticas. Conhecimentos atitudinais estão relacionados à natureza das atitudes do indivíduo nas diferentes situações a que é exposto em seus contatos grupais; envolvem valores e normas convencionadas no grupo social ao qual o indivíduo pertence.

Recebido: $05 / 04 / 07$

Aprovado: 20/05/08

Contato:

PUC SP

Coordenadoria Geral de Especialização, Aperfeiçoamento e Extensão

Rua da Consolação, 881

01301-000

São Paulo - SP

Brasil 